Contemporary Journal of Applied Psychology, Vol. 6, Number 2, 1-15, 2020

\title{
INFLUENCE OF AGE, AUTONOMY AND PERCEIVED SOCIAL SUPPORT ON PSYCHOLOGICAL DISTRESS AMONG STUDENTS OF INSTITUTES FOR SPECIAL NEEDS
}

\author{
*1 Oguntayo, Rotimi., \\ 2 Faworaja, Omolara R., \\ 3 Akintunde, Kayode A. \\ *1,2,3,4,5 Department of Psychology, University of Ilorin \\ Corresponding Author e-mail: rotimijoguntayo@gmail.com
}

\begin{abstract}
Evidence from past literature revealed that individuals with special needs have been neglected by parents, government and well-meaning authorities in Nigeria while numerous studies have shown that individuals with disability are facing a lot of psychosocial problems. This study examined the influence of age, perceived social support and autonomy on psychological distress among students with disabilities. The independent variables are social support and autonomy while dependent variable is psychological distress. This study adopted a correlational research design; 147 participants were sampled using simple randomisation. A questionnaire pack containing demographic factors (age, gender, religion, tribe), Social Support Questionnaire, Index of Autonomous Functioning and Distress Tolerance Scale were administered to the participants. Person product moment correlation, regression and one-way ANOVA were used to analyse the data. Results revealed a significant positive relationship between perceive social support and psychological distress $(\mathrm{r}=.190, \mathrm{p}<.05)$, and between autonomy and psychological distress $(\mathrm{r}=.240, \mathrm{p}<.01)$. Also, there was a joint significant prediction of perceived social support and autonomy on psychological distress $[R=.476$; $\left.\mathrm{R}^{2}=.226 ; \mathrm{F}(3,252)=13.40 ; \mathrm{P}<.05\right]$. However, age $[\mathrm{t}=2.828, \mathrm{p}<.05, \quad \beta=-.218]$, and autonomy $[\mathrm{t}=-4.165, \mathrm{p}<.05, \beta=-.333]$ did independently predict psychological distress. Adolescence stage had significant influence on psychological distress $(F(2,144)=7.84$, p.<.01); further result revealed a significant difference in the psychological distress of participants in late adolescence and early adolescence $(\mathrm{MD}=8.12 ; \mathrm{p}<.01)$. The study recommends that parents and stakeholders should encourage autonomy among people
\end{abstract}

Contemporary Journal of Applied Psychology, Vol. 6, Number 2, 1-15, 2020 
with disabilities. However, experts should be involved in order to be able to maintain appropriate autonomy that will alleviate psychological distress among these individuals.

Key words: Autonomy, Home for special needs, Social support, Disability.

\section{Introduction}

Psychological distress is one of the most serious pressing problems that the world is facing at present, especially among the adolescents with disabilities (Barrett, 2011), meanwhile the developing world like Nigeria has not been focusing this area especially looking at psycho-demographic factors causing psychological sequalae among this sets of individuals. According to United Nation, there is global view of about 180 million youths between ages of 10-24 who live with either physical, sensory, or intellectual disabilities and these individuals are at the risk of psychological distress (UN, 1990). Also, majority of over 150 million $(80 \%)$ of youths with disabilities who at the higher risks of mental illness live in the developing world (World Health Organisation (WHO), 2020). WHO further reveals that, a lot of disabled adolescents in sub-Sahara have been excluded from educational enrolment, economic benefits, social and cultural opportunities, this marginalization expose them to acute psychological distress. Studies have showed that individuals with disabilities have more tendency to develop lower general health condition, inadequate health care, and higher risk of psychological distress (Centre for Disease Control and Prevention \& National Institute on Disability and Rehabilitation Research, 2010; WHO, 2020). The current study is necessary in order to help identify factors barricading the mental health of people with special needs which will inform the preventive measures and health promotion recommendations aiming at improving the psychological wellbeing of people with disabilities.

According to the United Nations (2003), Nigeria has roughly 12 million citizens who are disabled; these disabilities include people with functional limitations such as physical, intellectual, or sensory impairment and medical or mental conditions (Siti, 2018). The history of this group can be characterized by marginalization, invisibility, the least cared for, and widespread discrimination from their families and the Nigerian society in general which predispose them to serious psychological distress (Siti, 2018). Most families in Nigeria who have at least a person with disability as family member are afraid of being ridiculed and laughed at by their neighbours and the public (Okafor, 2003); therefore, they tend to keep them either indoors and in isolation as well as depriving them of autonomy to function as expected with adequate supports. However, autonomy functioning may be one of those factors that could inform the state of psychological stance of this group of people.

Contemporary Journal of Applied Psychology, Vol. 6, Number 2, 1-15, 2020 
Despite the popular declaration on the concept of autonomy promulgated on "Rights of Persons with Disabilities" in the UN Convention in 2007, the relevance of autonomy to the physically challenge's psychosocial health is still unclear. Although, some societies have made and continue to make conscious efforts aimed at achieving this purpose through enactment of laws prohibiting discrimination based on race, ethnicity, national origin, gender, marital status, sexual orientation, age, colour, and disabilities (Akhidenor, 2007). Nigerians often see the disabled as a disgrace to their families; therefore, they are often confined to discrete places where people will not readily notice them. By such measures, the person with disability is prevented from participating in normal activities such as educational, economic, political, and social pursuits. Generally, families bear the brunt of caring for the disabled throughout their lives (Okafor, 2003). Those who cannot stay with their families are usually ostracized and their legal rights obstructed, including the right to live peacefully, and freedom of associations are threatened because of the general misconception that disabled people are either fiends or witches not worthy of human status. Thus, they often become homeless because of poverty and/or shame. According to Okafor (2003), people with physical disabilities in Nigeria have a heavy psychological burden due to social deprivations coupled with their struggle for economic survival.

Social supports can be referred to as using a variety of terms such as parental involvement, parental participation, parental support or parent-teacher collaboration. All these expressions refer to the co-operate support emanating from both the home and school in enhancing the child's functionality (Panter, Jones, van Sluijs \& Griffin, 2010). In addition, Garry \& RayleenLafaele, (2011) notes that, the effectiveness of both homebased and school-based parental involvement in facilitating academic achievement has been reported by several reviews and meta-analyses of the literature (Jeynes, 2007; Pomerantz, Moorman, \& Litwack 2007). Social support is one such enhancing psychosocial factor that has received considerable attention in child and adolescent literature however, this construct is scanty among individuals with special needs meanwhile, researchers have described social support as a salient construct that can impact social, physical and emotional wellness of individuals; this could be given by family members, friends, teachers and other notable persons in life generally (Israel \& Schurman, 1990). It has been shown that low levels of social support are related to a variety of psychological distress which could cause health related outcomes for adolescents (Chen \& Chen, 2012). Indeed, high levels of support can militate or reduce the negative impact of psychological stress on individuals with disabilities (Gros, Flanagan, Korte, Mills, Brady, \& Back, 2016). For instance, teenagers who receive more social support are not likely to have low social relations and hostile behaviours throughout adolescence and beyond. Social support has also been shown to positively associate with satisfaction of schooling experience in those with learning disabilities (DeSantis King, Huebner, Suldo, \& Valois, 2006). A study indicates that youth derive

Contemporary Journal of Applied Psychology, Vol. 6, Number 2, 1-15, 2020 
social support from a number of sources (e.g., parent/family, peers/classmates, and teachers), and social support from each source is associated with beneficial outcomes (Malecki \& Demaray, 2006). In early childhood, parental support seems to be most salient to development. Perceptions of supportive family relationships have been found to relate with internalize and externalize social and psychological behaviours (Rosario, Salzinger, Feldman, \& Ng-Mak, 2008). One of the factors that may probably increase psychological and subjective-wellbeing of adolescents is autonomous functioning (Gross et al., 2016).

Autonomy is referring to as ability to decide over oneself in some specific situations or instance but not in all aspects of life (Levension, Kjellin, \& Ostman, 2016). It the sense of volition, the need to be self-organized in experience and behaviour, and to possess ways of life in accordance with one's accepted sense of self. For example, choosing a career, choosing a school, cloth preference, learning etc. Only a limited number of researches considered whether autonomous functioning of people could aid there psychological wellbeing (Shogren \& Turnbull, 2006), specifically, studies considering autonomous functioning of people with special needs are low in sub-Sahara Africa. According to Shogren and Turnbull (2006), this lack of focus of researchers on developing the selfdependent of children with disabilities at home, within families, and at school may detrimentally limit the ability of individuals with disabilities to function both psychologically and in task-appropriate events compare to other colleagues.

Studies have showed that parents who support adolescents' autonomy and give more social support and are easily prone to promoting the growth of their children volitional or self-determination and the children maintain more social and psychological functioning (Igoglia, 2013), which, in turn, aggravate a better adjustment and more degrees of psychosocial wellness (Deci \& Ryan, 2000). Some studies have also revealed that parents that encouraged their children's autonomy are traced to developing children high academic performance, low depressive symptoms, and better behavioural functioning (Algood \& Harris, 2013; Inguglia, 2015). Throughout the phase of adulthood, the autonomy and social support as factors did build higher levels social and psychological functioning in children (Koepke \& Denissen, 2012).

Several studies have revealed that age is associated with distress among individuals with disabilities as it influences the rate of relationship with their parents and others (Deci et al, 2000; Igoglia, 2013; Koepke et al, 2012). Age of children encourages reciprocity and need to regulate autonomy and social connection in their relations with teachers, parents and others as children become socially and cognitively mature (Fuligni \& Pedersen, 2002). During the age of adolescence, there is generally an increase in psychosocial functioning among children (Inguglia, 2015). Probably, the mental health success and failure of students with special needs may depends largely on the achievement gained through social support and autonomy granted by caregiver(s). Children's experiences in

Contemporary Journal of Applied Psychology, Vol. 6, Number 2, 1-15, 2020 
school affect not just the development of their mental talents, but also their emotional adjustment, and psycho-social wellness (Algood et al., 2013). Looking at past studies, there is a major dearth of literature on whether psych-demographic factors (precisely, the age, social support and autonomy) can affect individuals with special needs' psychological wellness especially in sub-Sahara Africa. Even little studies that revealed social support as a factor were not from Nigeria nor conducted among the disabled individuals. Therefore, progress is needed, both in the understanding of the factors that contribute to or mitigate psychological distress of children with disabilities. Based on these existing gaps in the literature, the need to fill this gap arises, and the study is apt to address this challenge in postulating the following hypothesis:

1. There will be a significant relationship among age, perceive social support, autonomy and psychological distress.

2. There will be a significant joint and independent prediction of age, perceive social support and autonomy on psychological distress.

3. Individual who are in early adolescence will exhibit more psychological distress significantly compares with those who are in the middle adolescence and late adolescent.

\section{Method}

\section{Design}

This study adopted a correlational research design. The researchers chose this method because the study involved two settings with similar characteristics and interests like disabilities, gender age and education among others and because the independent variables of these study cannot be manipulated. The dependent variable is psychological distress while the independent variables are autonomy and social support. However, the study used the quantitative data collection techniques to achieve its objectives in the target region for the study.

\section{Setting}

This study was conducted in Ilorin metropolis, Kwara state and it involved the adolescents with special needs. Specifically, Kwara state School for special Needs in Apata-Yakuba, Ilorin and To-Omo-Re Training Institute located in Pipeline, Ilorin (both schools are public and private entity respectively). Kwara state School for special Needs was established in the year 1974 while in 1984, mentally retarded unit was included and the name of the school has been changed to Kwara State School for the Handicapped which seems derogatory, as a result it was renamed Kwara State School for Special Needs. Currently, the school has capacity to accommodate 460 pupils as at the time this research was conducted. To-omo-re Training Institute is a private rehabilitation centre for individuals with disabilities; it is situated at Pipeline road, Ilorin, Kwara state, Nigeria.

Contemporary Journal of Applied Psychology, Vol. 6, Number 2, 1-15, 2020 
These settings are suitable for this study because there are considerable number of students with special needs (learning and general disabilities) living within the selected community.

\section{Sampling techniques}

The sampling technique employed in this study was a simple randomization, this to make sure that all the participants have equal chance to partake in the study. The selection of students with special needs as participants was conducted purposively as the participants portrayed the traits required for this research work. consequently, participants were purposively selected from two schools a private and a public school.

\section{Participants}

The study utilised a total number of 147 respondents. Their age range were; between early adolescence 10 to 13 years were $21(14.3 \%)$, middle adolescence 14 to 17 years were $64(43.5 \%)$ and late adolescence 18 years and above $62(42.2 \%)$; there were 92 (62.6\%) males and $55(37.4 \%)$ females; the Christian participants were of $72(49.0 \%)$ and Muslims were 75 (51.0\%). Those from polygamous family were $34(23.1 \%)$ and monogamous family were $113(76.9 \%)$. The population were majorly Yorubas 114 (77.6\%), Igbo $19(12.9 \%)$ and Hausa/Fulani were $11(7.5 \%)$ and other tribes were 3 (2.0\%). These individual respondents were comprised of adolescents with; visual, physical, and learning disabilities as well as those with deaf and dumb.

\section{Procedure}

This study was approved by Faculty of Social Sciences Ethical Board, University of Ilorin. After the approval from the authorities of the selected schools, participants were selected using simple randomisation thus; those who were cognitively capable of responding to the questionnaires were selected and assembled into a hall (they are composed of people with visuals, physical and learning disabilities as well as deaf and dumb), tally A and B were administered to them and those who picked A tally were sampled as the participants for this study; this technique was used in order to make sure that all categories of disabilities were represented without any bias. The researchers explained the purpose of the study to both the teachers and the students. Those who were randomly selected and assented to participate in the study were the only ones included and after all, questionnaires were administered to them. Data were collected in 1 public and 1 private schools in Ilorin metropolis. Questionnaires were administered collectively in classrooms and the researchers waited to collect them. It took 20-30minutes to complete the questionnaires.

Contemporary Journal of Applied Psychology, Vol. 6, Number 2, 1-15, 2020 


\section{Instruments}

A structured questionnaire containing standardized instruments was used to collect data in this study. The questionnaire contained three (3) sections; the demographic information of the participants such as; age, gender, religion, family background and tribe were tapped. Three instruments were used in the study, namely: Index of Autonomous Functioning (IAF), (Weinstein, Przybylski \& Ryan, 2012); Social Support Questionnaire (SSQ) (Cohen, Mermelstein, Kamarck \& Hoberman, 1985); Distress Tolerance Scale (DTS) (Simons \& Gaher, 2005).

\section{Index of Autonomous Functioning (IAF)}

IAF was designed to measure level of autonomy primarily especially that which taps independence and detachment from parents rather than the sense of volition and selfregulation that characterizes the definition of autonomy, and as such it is expected that IAF should show only modest relations with the construct. Items were designed to represent each of the three subscales: authorship/self-congruence (items 1 to 5), interesttaking (Items 6 to 10), and susceptibility to control (items 11 to 15). Items were paired with a five-points rating scale with $1=$ "not at all true", $2=$ "a bit true", $3=$ "somewhat true", $4=$ "mostly true", and $5=$ "completely true." Three subscales achieved eigenvalues substantially higher than the rest, and were consistent with expectations: authorship/self-congruence (eigenvalue $=19.6$, accounting for $29 \%$ of the variance in the items), interest-taking (eigenvalue $=10.9,16 \%$ of variance), and susceptibility to control (eigenvalue $=4.0 ; 5.8 \%$ of variance). subscales, and found significant relations across all item pairing, with within-subscale correlations ranging from $\mathrm{r}=.50$ to $.81, \mathrm{p}<.001$, and inter-subscale item correlations ranging from .09 to $.32, \mathrm{p}$ .001 . The current study recorded a reliability of .81 . The scale items 7,9 and 10 are reversely scored while other items are directly scored. A score above 45 indicate higher autonomous individual.

\section{Distress Tolerance Scale (DTS)}

This measures the capacity to tolerate distressing or life frustration related events from a multidimensional framework. There are four components to the DTS model: an individual's (1) ability to tolerate emotions (tolerance); (2) assessment of the emotional situation as acceptable (appraisal); (3) level of attention absorbed by the negative emotion and relevant interference with functioning (absorption); and (4) ability to regulate emotion (regulation). Cronbach's alpha as computed by authors for the single secondorder factor and each of the four first-order factors were as follows: DTS total score $=.91$, Tolerance subscale $=0.66$, Absorption subscale $=0.83$, Appraisal subscale $=0.85$, and Regulation subscale $=0.77$. The present study recorded an overall Cronbach Alpha of .82 . Items are rated on a 5-point Likert scale (5=strongly disagree, 4=Disagree, 3=Undecided, 
$2=$ Agree and $1=$ strongly agree), with 42 being the higher minimum scores corresponding to greater levels of distress tolerance.

\section{Social Support Questionnaire}

This 12-item scale measures perceptions of social support. It was adapted and developed by Cohen, Mermelstein, Kamarck \& Hoberman (1985); it is a shortened version of the original 40 items of Interpersonal Support Evaluation List (ISEL) (Cohen \& Hoberman, 1983). This questionnaire has three different subscales designed to measure three dimensions of perceived social support. With these dimensions are: 1.) Appraisal Support, 2.) Belonging Support, 3.) Tangible Support. The response is in multiple thus; $1=$ definitely false, $2=$ probably false, $3=$ probably true and $4=$ definitely true. Scoring: Items 1, 2, 7, 8, 11, and 12 are reverse scored. Items 2, 4, 6, 11 make up the Appraisal Support subscale Items 1, 5, 7, 9 make up the Belonging Support subscale Items, 3, 8, 10, 12 make up the Tangible Support subscale. Cronbach's alphas for the ISEL-12 total score were all above .70 in the full sample, English and Spanish, and overall Cronbach's alphas for the subscale scores were inadequate for Appraisal (.65), Belonging (.62), and Tangible (.57) for the full sample. For the English responders, internal consistencies for the Appraisal (.71) and Belonging (.76) subscale scores were adequate, whereas internal consistency for the Tangible (.66) subscale score was not. For the Spanish responders, internal consistencies for all three subscale scores were inadequate $(.54-.63)$. The Appraisal, Belonging, and Tangible subscales (scores range $0-12$ ) composed of four items each. The present study recorded a Cronbach Alpha of .87. Scores above 24 indicate high perceived social support of individual participant.

\section{Statistical Analysis}

Descriptive statistics was used to analyze the demographic information, while hypothesis 1 was analyzed using Pearson product correlation. Hypothesis 2 was analyzed with multiple regression and 3 analyzed using One-way Analysis of Variance (ANOVA).

\section{Results}

Table 1; Summary of Hypothesis One Showing Pairwise Inter-Variable Correlations using Pearson Product Moment Correlations

\begin{tabular}{llcccll}
\hline Variable & 1 & 2 & 3 & 4 & $\bar{x}$ & SD. \\
\hline 1 Age & - & & & & 2.70 & 1.61 \\
2 Perceived Social Support & .049 & - & & & 30.44 & 6.67 \\
3 Autonomy & $.283^{* *}$ & .272 & - & & 50.62 & 9.30 \\
4 Psychological Distress & $.313^{* *}$ & $.190^{*}$ & $.420^{* *}$ & - & 46.78 & 10.25 \\
\hline
\end{tabular}

** Correlation is significant at the $0.01 * *$ level (1-tailed). 
* Correlation is significant at the $0.05 *$ level (2-tailed).

Table 2 results showed that there is a significant positive relationship between age and psychological distress $(\mathrm{r}=.313, \mathrm{p}<.01)$, perceive social support and psychological distress $(\mathrm{r}=.190, \mathrm{p}<.05)$ and autonomy and psychological distress $(\mathrm{r}=.240, \mathrm{p}<.01)$. This indicate that as age, social support and autonomy increase or decrease psychological distress may also be increase or decreasing can be used to explain psychological distress among the sampled participants. Hence, the need to test other hypothesis regarding the independent variables on dependent variable arise as presented below:

Table 2; Summary of Hypothesis Two Showing Significant Multiple Regression of Age, Perceived Social Support and Autonomy on Psychological distress

\begin{tabular}{llllllll}
\hline Variables & $\mathrm{R}$ & $\mathrm{R}^{2}$ & $\mathrm{~F}$ & $\mathrm{Sig}$ & $\mathrm{Beta}$ & $\mathrm{T}$ & $\mathrm{Sig}$. \\
\hline Age & & & & & -.218 & 2.828 & .005 \\
Perceived Social Support & .476 & .226 & 13.40 & .000 & .092 & 1.198 & .233 \\
Autonomy & & & & & -.333 & 4.165 & .000 \\
\hline$* * \mathrm{p}<.01, * \mathrm{p}<.05$ & & & & & & &
\end{tabular}

Hypothesis two which states that age, perceived social support and autonomy will jointly and independently significantly predict psychological distress. The result shows that there is a joint significant prediction of age, perceived social support and autonomy on psychological distress $\left[\mathrm{R}=.476 ; \mathrm{R}^{2}=.226 ; \mathrm{F}(3,252)=13.40 ; \mathrm{P}<.05\right]$ where $23 \%$ of changes observed in psychological distress was strictly account for by age, perceived social support and autonomy. While age $[\mathrm{t}=2.828, \mathrm{p}<.05, \beta=-.218]$ and autonomy $[\mathrm{t}=-4.165$, $p<.05, \beta=-.333]$ did independently predict psychological distress. However, perceived social support did not predict psychological distress independently. Therefore, this hypothesis is accepted for this study.

The results for hypothesis three that individuals who are in early adolescence will exhibit more psychological distress compare with those who are in middle adolescence and late adolescence was tested using One-way-ANOVA as presented in Table $4 \mathrm{a}$ and $4 \mathrm{~b}$ :

Table 4a; Summary of Hypothesis Three Showing the significant influence of Stages of Adolescence of Participants on Psychological distress

\begin{tabular}{llllll}
\hline Source & SS & Df & MS & F & P \\
\hline Stage of Adolescence & 1505.902 & 2 & 752.951 & 7.84 & $<.01$ \\
Error & 13827.69 & 144 & 96.026 & & \\
Total & 15333.592 & 146 & & & \\
\hline
\end{tabular}

Result from table 4a showed that stages of adolescence of participants had significant influence on psychological distress $\left(\mathrm{F}_{(2,144)}=7.84\right.$, p. $\left.<01\right)$. Consequently, post hoc

Contemporary Journal of Applied Psychology, Vol. 6, Number 2, 1-15, 2020 
analysis was analysed using multiple comparisons in order to ascertain the magnitude significant determinant of F-Value,. Consequently, LSD post hoc analysis was used to compare the three groups. The results are shown in Table $4 \mathrm{~b}$ shown below;

Table 4b; Showing the Summary of LSD analysis of the influence Stages of Adolescence on Psychological distress.

\begin{tabular}{|c|c|c|c|c|c|c|c|}
\hline Groups & $\mathbf{N}$ & $\bar{X}$ & SD & 1 & 2 & 3 & 4 \\
\hline 1 Early Adolescence & 21 & 42.29 & 10.4 & 1 & & & \\
\hline 2 Middle Adolescence & 64 & 44.73 & 7.15 & 2.45 & 1 & & \\
\hline 3 Late Adolescence & 62 & 50.40 & 11.8 & $8.12 *$ & $5.67 *$ & 1 & \\
\hline
\end{tabular}

Note: $* * p<.05 ; * p<.01$.

The post-hoc result presented in Table $4 \mathrm{~b}$ shows that a total adjusted mean of 50.40, of late adolescence stage individuals $(n=62)$ exhibited more psychological distress when compared to those in middle $(\mathrm{n}=64)$ with adjusted mean of 2.45 and early adolescence counterparts $(n=21)$ with a total adjusted mean of 42.29 . The result revealed a significant difference in the psychological distress of those with late adolescence and early adolescence $(\mathrm{MD}=8.12 ; \mathrm{p}<.01)$. Also, those in late adolescence and middle adolescence, and middle adolescence ( $\mathrm{MD}=5.67 ; \mathrm{p}<.01)$. Meanwhile, there is no significant difference in the middle adolescence and early adolescence ( $\mathrm{MD}=2.45$; $\mathrm{p}>.01$ ). The outcome of hypothesis four was not in agreement with the stated hypothesis four which stated individuals who are who in early adolescence will exhibit more psychological distress compare with those who are in middle adolescence and late adolescence. Therefore, the stated hypothesis four is not confirmed.

\section{Discussion}

Some findings from this study tend to support what many other similar researchers have found. Results showed that there was a significant relationship between age, autonomy, social support and psychological distress. This supports the previous study which found that age, autonomy and social relatedness significantly associated with psychological distress (Ingoglia et al., 2013). This study found that adolescents' autonomy was positively related to psychological wellness Also, consistent evidence exists that there is a relationship between social support and psychological distress (Chu, Saucier, \& Hafner, 2010; Rueger, Malecki, Pyun, Aycock, \& Coyle, 2016). These studies found that adolescents' age, and social support did positively related to psychological wellness. This could be interpreted that; age, autonomous functioning and social support are factors that could be used to explain psychological distress.

Also, hypothesis three showed that, there is a joint significant prediction of age, perceived social support and autonomy on psychological distress. However, perceived social support did not predict psychological distress independently but autonomy. These

Contemporary Journal of Applied Psychology, Vol. 6, Number 2, 1-15, 2020 
findings are similar to findings of the previous studies (Inguglia, 2015; Kaitholil, 2002) which revealed that though social support is one of the most important factors in predicting the physical health but children with autonomy tend to have lesser psychopsychological distress, ranging from childhood through old adolescence age. Another study by Deci \& Ryan (2000) also stressed the that three dimensions of needs (autonomy, competence and relatedness) often contribute to the adolescents' general well-being and especially decreased their psychological distress. The need for autonomy is a basic human propensity to gain independence and avenue to maintain both social and psychological functioning to aid personal respect. This implies that autonomy is a great factor to consider in increasing the psychological wellness of individuals with special needs and this encourage them to function with immediate caregivers. Looking at this result, it is possible to assume that adolescents with special needs tend to score high on psychological distress when they perceived that their autonomy are restricted abruptly. However, it was observed that, there was an insignificant prediction of social support on psychological distress; though this result contracted most previous studies, the reasons may be that at this age, adolescents spend more time with their age-groups compared to families or caregivers as most of them move away from home to school, they may tend to enjoy their colleagues' company and use it to compensate for the social support derived from family members or caregivers. Also, it is a transitional stage in adolescents to leave adolescence to early adulthood and they enjoy exploring their identity and this could shape their psychological distress. These factors may serve as contributors to the present result.

Further result of hypothesis three which stated that individuals who are in early adolescence will exhibit more psychological distress compare with those who are in middle adolescence and late adolescence revealed that stages of adolescence of participants had significant influence on psychological distress. It further revealed that late adolescence stage individuals exhibited more psychological distress when compared to those in middle and early adolescence counterparts. Therefore, there is a significant difference in the psychological distress of those with late adolescence and early adolescence. Meanwhile, there is no significant difference between those in middle adolescence and early adolescence. Though, these results contradicted the previous results such as; the research by Carstensen \& Charles, (2008) which suggested that older adults experience less distress than younger people. However, Djernes, (2006) shared the view with the present study that psychological distress in older persons occurs at a higher rate in institutional settings than in private household settings. Expectedly, the age difference was found in psychological distress levels reported by our participants, age variability could be factors considering levels of parental support and autonomy for these individuals. Indeed, as hypothesized, adolescents were found to be different at level of psychological distress of the respondents. This finding suggests that, teens with disabilities at older age tend to feel less distress psychologically compare to those in early

Contemporary Journal of Applied Psychology, Vol. 6, Number 2, 1-15, 2020 
and middle adolescence. Yet these results leave one question unanswered: Do emerging early adolescence of individual with disabilities predispose them to psychological distress than those in middle and late adolescence? This implicated further research.

\section{Conclusion}

The findings of this study seem to support what many studies have found though some results in the present study contradicted the past findings which could be as a result of some contextual and cultural difference; the results showed that there is a positive significant relationship between age, autonomy and social supports and psychological distress, this implies that age, social support and autonomy can be used to explain psychological distress. So also, there was a significant joint and independent prediction of age, perceived social support and autonomy on psychological distress, meaning that combination of these factors can be used to predict psychological distress among the sampled participants. However, perceived social support did not predict psychological distress independently while age and autonomy did. Further results showed that older participants in late adolescence manifest higher level of psychological distress among the sampled participants more compared to others.

\section{Recommendations}

Considering the findings of the present study, it is therefore recommends that:

i. Authorities and stakeholders of schools for special needs should encourage sense of autonomy among their students and also build trust in them to possibly engage in tasks independently and if perhaps they did not perform to the expectation, the caregivers should render social involvement in effective and positive manner to alleviate their psychological distress.

ii. Older adolescents in the special schools should not be imposed on, instead they should be asked on what is of interest to them in matter of vocational or educational preference to promote their volitional or self-determination growth and performance in order to further maintain their social functioning. Better still, social workers, psychologists and occupational therapists should be involved hence in the rehabilitation process of these individuals to achieve robust outcomes that will aid more social functioning among these individuals in special education units.

iii. Social media awareness to parents and caregivers will also be of benefit to the general society on how to give a moderate autonomy to children with disabilities (those with special needs especially) in a supportive way to foster stronger social functioning in them.

Contemporary Journal of Applied Psychology, Vol. 6, Number 2, 1-15, 2020 
iv. Involvement of these students in school social activities and allow them to choose their preference such as; sporting and athletic activities should be encouraged to alleviate their psychological wellbeing.

\section{References}

Akhidenor, C.D. (2007). Nigerians' Attitudes toward People with Disabilities. (Doctoral dissertation). Capella University, USA.

Algood, C.L. \& Harris, C. (2013). Parenting Success and Challenges for Families of Children with Disabilities: An Ecological Systems Analysis Journal of Human Behavior in the Social Environment, 23:126-136.

Barrett, M. (2011). Psychological Distress of Adolescents with Learning Disabilities; The Moderating Effects of Age, Gender and Social Supports. A Master of Education Thesis Submitted to School of Graduate Studies, Memoria University of Newfoundland, St. John's Newfoundland.

Carstensen, L.L. \& Charles, S.T. (2008). Emotion in the second half of life. Current Directions in Psychological Science, 7(5), 144-149.

Centre for Disease Control and Prevention \& National Institute on Disability and Rehabilitation Research, (2010). Disability and Secondary Conditions. Retrived from: http://wonder.cdc.gov/data2010/

Chen, S., \& Chen, A. (2012). Youth physical activity behaviour and energy-balance knowledge: an expectancy-value perspective. Journal of Teaching Physical Education, 31:329-43.

Cohen, S., \& Hoberman, H. (1983). Positive events and social supports as buffers of life change stress. Journal of Applied Social Psychology, 13, 99-125.

Cohen, S., Mermelstein, R., Kamarck T., \& Hoberman, H.M. (1985). Measuring the functional components of social support. In Sarason, I.G. \& Sarason, B.R. (Eds), Social support: theory, research, and applications. The Hague, Netherlands: Martinus Niijhoff

Clough, P. \& Nutbrown, C. (2004). Special Educational Needs and Inclusion: Multiple Perspective of Preschool Educators in the UK. Journal of Early Childhood Research, 2(2), 191-211. https://doi.org/10.1177/1476718X04043015.

Chu, P. S., Saucier, D. A., \& Hafner, E. (2010). Meta-analysis of the relationships between social support and well-being in children and adolescents. Journal of Social and Clinical Psychology, 29(6), 624-645

Deci, E.L. \& Ryan, R.M. (2000). The "What" and "Why" of goal pursuits: human needs and the self determination of behavior. Psychological Inquiry, 11, 227-268. doi:10.1207/S15327965PLI1104_01.

DeGarmo, D.S. \& Martinez, C.R.J. (2006). A culturally informed model of academic well-being for Latino youth: The importance of discriminatory experiences and social support. Family Relations, 55(3), 267-278.

Contemporary Journal of Applied Psychology, Vol. 6, Number 2, 1-15, 2020 
DeSantis King, A.L., Huebner, S., Suldo, S.M. \& Volois, R.F. (2006). An ecological view of school satisfaction in adolescence: Linkages between social support and behavior problems. Applied Research in Quality of Life, 1, 279-295.

Djernes, J.K. (2006). Prevalence and predictors of depression in populations of elderly: A review. Acta Psychiatrica Scandinavica, 113(5), 372-387.

Garry, H.G. \& RayleenLafaele, R. (2011). Barriers to parental involvement in education: an explanatory model. Educational Review Vol. 63, No. 1, 37-52.

Gros, D. F., Flanagan, J. C., Korte, K. J., Mills, A. C., Brady, K. T. \& Back, S. E. (2016). Relations among social support, PTSD symptoms, and substance use in veterans. Psychol Addict Behav., 30(7):764-770. doi:10.1037/adb0000205

Israel, B. \& Schurman, S. (1990). Social support, control, and the stress process. In Glanz, K.Frances, M. \& Rimer, B. (Eds.), Health behavior and health education: Theory, research, and practice (pp. 187-215). San Francisco, CA: Jossey-Bass.

Inguglia, C. (2015). Autonomy and Relatedness in Adolescence and Emerging Adulthood: Relationships with Parental Support and Psychological Distress. Journal of Adult Development, 22(1), 1-13.

Ingoglia, S., \& Lo Cricchio, M. G. (2013). Italian Adaptation of the "Autonomy and Relatedness Coding System". Europe's Journal of Psychology, 9, 461-478.

Jeynes, W.H. (2007). The relation between parental involvement and urban secondary school student academic achievement: A meta-analysis. Urban Education 42, no. 1: $82-110$.

Kaitholil, C. (2002). Communion in community. Mumbai: Society of St Paul Bandra.

Koepke, S., \& Denissen, J. J. A. (2012). Individuation and identity development in adolescence and emerging adulthood: Conceptual clarifications and an integrative model. Developmental Review, 32, 67-88.

Levension, H., Kjellin, L., \& Ostman, M. (2016). Autonomy and Severe Mental Illness: The Relationship between Social and Functioning. SOJ Nursing and Healthy Care, 2(2): 1-5.

Malecki, C.K. \& Demaray, M.K. (2006). Social support as a buffer in the relationship between socioeconomic status and academic performance. School Psychology Quarterly, 21, 375-395.

Okafor, L. (2003). Enhancing business-community relations: Sir David Osunde Foundation case study. Retrieved from; www.undp.org.ng.

Panter, J.R., Jones, A.P., van Sluijs, E.M., \& Griffin, S.J. (2010). Attitudes, social support and environmental perceptions as predictors of active commuting behaviour in school children. Journal of Epidemiology of Community Health, 64, 41-48

Pomerantz, E.M., Moorman, E.A. \& Litwack, S.D. (2007). The how, whom and why of parentse involvement in children's academic lives: More is not always better. Review of Educational Research 77, no. 3: 373-410.

Contemporary Journal of Applied Psychology, Vol. 6, Number 2, 1-15, 2020 
Rosario, M., Salzinger, S., Feldman, R.S. \& Ng-Mak, D.S. (2008). Intervening processes between youths' exposure to community violence and internalizing symptoms over time: The roles of social support and coping. American Journal of Community Psychology, 41(1), 43-62.

Schultz, G.F. \& Switzky, H.N. (1990). The development of intrinsic motivation in students with learning problems. Preventing School Failure, pp. 14-20.

Shogren, K.A. \& Turnbull, A.P. (2006). Promoting self-determination in young children with disabilities: The critical role of families. Infants \& Young Children, 19(4), 338.

Siti, B. (2018). The Influence of Parents' Involvement on Children with Special Needs' Motivation and Learning Achievement. International Education Studies; Vol. 11, No. 4. URL: https://doi.org/10.5539/ies.v11n4p96.

Simons, J., \& Gaher, R. (2005). The Distress Tolerance Scale: development and validation of a self-report measure. Motivation and Emotion. 29:83-102.

Soenens, B. \& Beyers, W. (2012). The cross-cultural significance of control and autonomy in parent-adolescent relationships. Journal of Adolescence, 35, 243-248.

Suldo, S.M. \& Shaffer, E.J. (2008). Looking beyond psychopathology: The Dual-Factor Model of mental health in youth. School Psychology Review, 37(1), 52-68.

Rueger, S. Y., Malecki, C. K., Pyun, Y., Aycock, C., \& Coyle, S. (2016). A meta-analytic review of the association between perceived social support and depression in childhood and adolescence. Psychological Bulletin, 142(10), 1017-1067

United Nations. (1990). Department of International Economic and Social Affairs, Statistical Office. Disability Statistics Compendium. Statistics on Special Population Groups, Series Y, No. 4, New York: UN

United Nations population and vital statistics report. (2003). Retrieved April 12, 2004, from http://unstats.un.org/unsd/disability/disform.asp.

Weinstein, N., Przybylski., A.K. \& Ryan, R. M. (2012). The index of autonomous functioning: Development of a scale of human autonomy. Journal of Research in Personality, 46, 397-413. Retrieved from: www.elsevier.com/locate/jrp on 23/10/2018

World Health Organisation. (2020). Mental health, poverty and development. WHO

Forum.

Retrieved

From:

https://www.who.int/mentalhealth/policy/development/en/

Contemporary Journal of Applied Psychology, Vol. 6, Number 2, 1-15, 2020 